\title{
Student-Centered Learning in Oman: Challenges and
}

\section{Pitfalls}

\author{
Ogadimma C. Emenyeonu \\ Department of Communication Studies, College of Applied Sciences, Nizwa
}

Accepted: September 04, 2012 Published: October 20, 2012

Doi:10.5296/ijld.v2i5.2549ＵRL: http://dx.doi.org/10.5296/ijld.v2i5.2549

\begin{abstract}
Student-centered learning (SCL) is aimed at developing pedagogy that probes into students learning in regard to what they experience and how they engage in the learning context or environment. This paper aims to review what is meant by student-centered learning in the context of Oman, and how this can be achieved. It goes further to explore challenges that tend to deter the implementation of SCL with a view to providing recommendations to improve and enhance SCL in Oman. Following data collected from the focus group discussions, the study reveals that language, culture, lack of student exposure, exported teaching materials, poor perception of SCL by students, among others, is they major obstacles facing SCL in Oman. Based on the findings, the author recommends that for SCL to take root in Oman there should be attitudinal change on the part of students with regard to a better understanding of what SCL is and why it is desirable, and students of opposite genders should be encouraged to work together to articulate their ideas in a disciplined social process of inquiry.
\end{abstract}

\section{INTRODUCTION / LITERATURE REVIEW}

Learning systems that promote student-centered learning should among other things provoke independent reasoning, problem solving and critical thinking. This can only be achieved if teachers have ample or excellent ideas, knowledge, and examples in regard to how to create a class room that is more active, interactive, and communicative. As Brenda Hall (2006) write, student centered learning is put in place to help students to find out their own learning styles, to know and understand their motivation, and to acquire effective study skills that will be valuable throughout their lives. Consequently the focus of the student centered learning is on student outcome rather than on teaching. There is therefore a conceptual shift from the teacher to the student. This paradigm shift from teaching to learning has encouraged the empowerment of the student rather than the teacher. Whereas the teacher-centered learning emphasizes the teacher as an expert transmitting knowledge to a novice, the student centered learning in contrast focuses on the roles students play to achieve learning. This supports the assertion of Kember (1997) that knowledge is constructed by students and that the lecturer is a facilitator of learning rather than a presenter of information. In a more inclusive analysis of the meaning of student centered learning, Lea et al (2003) opine that student centered learning would include: reliance on active rather than passive learning, an emphasis on deep understanding, increased responsibility and accountability on the part of the student, an increased sense of autonomy in 
the learner, an interdependence between teacher and learner, mutual respect within the learner-teacher relationship, and finally a reflexive approach to the teaching and learning process on the part of both teacher and learner.

In effect traditional pedagogy of teaching was built on the assumption that learners acquired information passively, that knowledge could be passed from one person to another. Paulo Freire, a renowned education theorist argues strongly against this method of learning. Freire in one of his theories called 'The banking concept of education' compares two concepts of education - the banking and problem posing. In the banking system students are viewed as empty and blank to be filled by the teacher. This simply transforms and reduces the students into receiving objects. Teachers in this set up take absolute control because they see students as passive. They determine what will be learned and how it will be learned, and 'force feed' information to students. On the other hand in a problem posing set up, Freire posits that students and teachers interact in a dialogue to teach one another. This method makes students to be active, and empowered to engage in independent thoughts or critical thinking. Put differently problem posing education allows people to develop their human natures fully because it depends on dialogue (communication), recognizes the relationship between people and the world, encourages or supports inquiry, and leads to change or transformation. (http://www.infed.org/thinkers/et-freir.htm).

Garvin (1991) is of the opinion that the traditional model of teaching is based on the idea of teaching as "telling", with the primary objective of transferring knowledge from an expert (the teacher) to novices (students). In this model critical aspects of teaching like syllabus, pace and sequencing and mode of presentation are controlled by the expert. Thus the expert lectures and the novices record and absorb what is taught by the expert. Garvin goes on to argue that in this type of model, interactions between teacher and students are just to the point of very short question and answer sessions, and there is hardly any interactions among and or between students.

Inactive learning, as opposed to student-centered learning, encourages students to study for utility - a case where they memorize and regurgitate facts without understanding them just to pass exams. Active learning promotes lifelong learning.

A classroom that encourages dialogue/interaction comes into terms with collaborative learning technique. Advocates of collaborative learning are of the opinion that students should not be completely dependent on the teacher as the authority on either subject matter or content, rather they ought to think for themselves - be critical thinkers. Pederson and Liu (2003), Gokhale (1995), are of the view that the concept of collaborative learning involves the grouping and pairing of students for the purpose of achieving academic goal. There is a sort of skill and ability mix in this case as students at various performance levels work together in small groups to achieve a common goal. What is interesting here is that the students are responsible for one another's learning as well as their own. Research findings on collaborative learning, Gokhale (1995), Bean (1996), Brufee (1999), claim that active interaction/exchange of ideas in small groups increases interest among members and also encourages critical thinking.

Writing on the challenges of SCL in Vietnamese Higher Institutions, Thanh, (2010) examines the causes that create the problems and hidden belief that keep traditional perceptions about learning permanent. This study reveals that to change the students' current learning approach to student-centeredness does not need a set of new principles to be imposed on learners. Rather, 
Thanh is of the view that, there need to be changes in both school infrastructures (introducing teaching materials that aid SCL), and people's perceptions (moving from teacher centered to student centered approach).

Sablonnière et al (2009) while probing the "Challenges of applying a student-centered approach to learning in the context of Kyrgyzstan, argue that school attempting to prepare more students for college and careers by adopting and implementing student-centered approaches to learning face herculean tasks in their attempts to go beyond the status quo. They contend that any educational reform effort is liable to encounter barriers, but that the difficulties inherent in changing the traditional nature of teaching and the culture of classrooms present particular problems. They conclude that understanding these dynamics at the outset of planning for reform will support efforts to prioritize student needs, motivations, and interests and put them at the center of educational practice.

Brush and Saye (2000) in a study on "Implementation and Evaluation of a Student-Centered Learning Unit: A Case Study", posit that successful implementation of student-centered learning requires support and enhancements to the learning climate which teachers and curriculum developers must integrate into existing curricula. Quoting (Hannafin et al 1999; Brush and Saye, 1999) Brush and Saye point out that the enhancements include problem contexts, evaluation mechanisms, and tools or scaffolds to support both student learning and teacher management.

The table below summarizes some of the differences between teacher centered learning and student centered learning.

Table 1: Summary of the differences between traditional model and student centered learning

\begin{tabular}{|c|c|}
\hline Teacher centered learning & Student centered learning \\
\hline Lacks individual accountability & Individual accountability \\
\hline Passively receives information from teacher & Actively involved in learning \\
\hline Follow course profile & Divide lesson for group work \\
\hline $\begin{array}{l}\text { Sitting arrangement is independent } \\
\text { work }\end{array}$ & Sitting is arranged to encourage group \\
\hline $\begin{array}{l}\text { Detailed information, too much teacher } \\
\text { providing info. } \\
\text { talking time }\end{array}$ & Facilitates learning, students share in \\
\hline Power primarily with teacher & Power primarily with students \\
\hline Student passive & Student active \\
\hline Low level of student choice & High level of student choice \\
\hline
\end{tabular}

\section{TEACHER'S ROLE IN ENHANCING SCL.}

Student-centered learning does not occur by happenstance. It is a deliberate, planned activity where the teacher plays an enormous role influencing it. The following table adapted mostly from Jim Scrivener's Book, Learning Teaching, explains the teachers role in influencing the learning environment. (Scrivener 2005)

\begin{tabular}{|l|l|}
\hline Learning Environment. & Teacher's Role \\
\cline { 2 - 2 } $\begin{array}{l}\text { Classroom } \\
\text { Atmosphere }\end{array}$ & $\begin{array}{l}\text { The teacher tries to create and sustain an appropriate, warm and focused } \\
\text { working environment }\end{array}$ \\
\hline
\end{tabular}




\begin{tabular}{|c|c|}
\hline Organisation & $\begin{array}{l}\text { Teacher may take an active role in organizing how time, space, materials } \\
\text { etc are used. }\end{array}$ \\
\hline Support & $\begin{array}{l}\text { The teacher can provide positive support and encouragement to students } \\
\text { to take active role. }\end{array}$ \\
\hline $\begin{array}{l}\text { Enhancing guided } \\
\text { discovery }\end{array}$ & $\begin{array}{l}\text { Teacher elicits answers, formulates questions, give partial examples, } \\
\text { encourage hypothesis, etc that lead the students to work out answers for } \\
\text { themselves. }\end{array}$ \\
\hline $\begin{array}{l}\text { Presenting content } \\
\text { information }\end{array}$ & $\begin{array}{l}\text { Teacher can explain, lecture, and answer questions etc on areas of the } \\
\text { learning content. }\end{array}$ \\
\hline Materials and tasks & $\begin{array}{l}\text { Teacher can propose, suggest or select what work is to be done in class } \\
\text { and the text and materials to be used. }\end{array}$ \\
\hline Monitoring & The teacher can monitor what is happening in the class \\
\hline Informative feedback & $\begin{array}{l}\text { The teacher can give objective information that may help the learning } \\
\text { process. For example correcting bad, negative, or insufficient } \\
\text { answers/information given by students }\end{array}$ \\
\hline Habit of learning & $\begin{array}{c}\text { The teacher can, as part of regular timed lesson, provide a sense of form, } \\
\text { regularity and concreteness to an otherwise more formless learning } \\
\text { process. }\end{array}$ \\
\hline $\begin{array}{l}\text { Structuring } \\
\text { sequencing }\end{array}$ & $\begin{array}{l}\text { The teacher can suggest or help select what to study and how to organize } \\
\text { the programme of learning and the shape of individual lessons. }\end{array}$ \\
\hline Teacher's movement & $\begin{array}{l}\text { The teacher's presence has to be felt throughout the whole class. This can } \\
\text { be done by the teacher moving from one end to the other, especially to } \\
\text { places of inactivity. }\end{array}$ \\
\hline
\end{tabular}

HOW TO FOSTER SCL. The following discussion is an attempt to explain some ways to foster SCL

1. Students' involvement in curriculum design: In this situation, students should be actively involved in choosing what to study and how to study what is chosen. This can be done by modularization of courses. This system gives students some degree of freedom in choosing what modules they will study. This method is in practice in EU undergraduate courses since 2006. Researches recognized the importance of students' involvement in curriculum development. This helps students to define their own learning objectives and outcomes. Another aspect of course design that encourages student-centered learning is the writing of the learning outcomes and or objectives. This focuses on what the student will be able to do rather than the content covered by the teacher. The implication is that in SCL, outcomes is something like: "By the end of this course/module, the student will be able to..., while in the traditional set up, the learning objective/outcome is; "This course will cover..." The former emphasises the process of competence on the part of the student rather than the content covered by the teacher in the later. 
2. Teaching and learning methods: The teaching and learning methods applied should be geared toward empowering students in the classroom. The power that is hitherto centered on the teacher should be deemphasized if SCL must take place. The following methods should be considered when considering student-centered learning and or teaching methods. Students should be given independent projects, involved in group discussions, debates, field trips. They should keep reflective diaries, choose their own topics/ projects, make presentations, come up with portfolio developments, and be involved in peer assessment, etc. In a focus group discussion the author had with both students and teachers on teaching/learning methods that effect SCL, both the respondents were of the view that students feel proud to be in charge of their learning destiny as it were, rather than when they were being spoon-fed information by the teachers. The students feel they can do or achieve something with their own initiatives. They are emboldened to be somewhat independent. One student said "I feel very happy whenever I do my projects without much reference to, or interference by my teacher. It shows I am improving in my study'.

3. Assessment methods: Assessment methods that highlight SCL should emphasize giving of advice and learning function rather than giving of marks and grades; personal improvement rather than competition among students; self-assessment to help students take responsibility for their own learning. Black (1999). Put differently feedback to students on their learning improves and advances the students learning rather than the traditional examination method. Formative assessments should focus on the students by calling attention to the students' learning lapses and areas they need to improve on. Formative assessment would include all forms of feedbacks or comments on students' assignments highlighting their strengths and weaknesses. Apart from this, research conducted by Brown et al (1994) indicates that students can be part of the assessment process by being involved in choosing the assessment task, setting the assessment task, discussing the assessment criteria, making self-assessment comments/peer feedback.

METHODOLOGY: The major thrust of this study is to find out what constitutes obstacles to implementing SCL in Oman. In doing so the author employed the focus group discussion/interview to generate data. This method was used as it is the most apt (Liamputtong, 2011), to get first hand information of teachers' and students' experiences in the classroom, and to elicit a more detailed response from the respondents. Further this method was used because it is a sound qualitative research used in collating answers to questions on peoples' perceptions, understanding, and explanation of certain phenomena.

DESIGN / PARTICIPANTS: A focus group interview/discussion comprising of thirty teachers was conducted. The teachers were placed in three groups of 10 each. Each group was made up of 5 men and five women. Two groups were drawn from College of Applied Sciences, (CAS) Nizwa, while the third group was from International College of Engineering and Management, Muscat. The number of staff in each college determined the number of group(s). The participants from each group came from different departments, and socio-cultural backgrounds. Sixty students were also selected from the same colleges. They were placed in three groups, two groups of twenty each from CAS Nizwa and one from International College of Engineering and Management, Muscat. The students were aged 16-24 representing various disciplines and different levels of study - from foundation to final year. Both the teacher/student participants were randomly selected. The interview featured open-ended questions. The moderator used probing as a technique to elicit honest opinions and encourage 
lively discussions. The questions bothered on: 1 . Why students don't take active part in the classroom. 2. Mentioning and explaining factors that have aided or abated SCL. 3. The methods teachers use to encourage SCL. 4. What roles students and teachers play in the classroom? 5. Difficulties teachers face in implementing SCL. 6. Students' perception of SCL. 7. How SCL can be fostered.

SETTING: College of Applied Sciences, Nizwa, and International College of Engineering and Management, Muscat.

ANALYSIS OF INTERVIEWS/DISCUSSIONS: The author summarized the opinions of the discussants which were almost similar. Quoting them verbatim would sound repetitious, cumbersome and boring. However in certain cases the author quoted the participants as is the practice in the analysis of focus group studies.

\section{BARRIERS TO SCL IN OMAN}

In as much as SCL is desirable, there are many challenges that have threatened its implementation in Oman. We will make an attempt to discuss these challenges in this section. The findings are based on focus group discussions with teachers and students in the sample colleges with regard to their experiences in the classroom. Both the teachers' groups and the students' groups were united in identifying the following barriers to SCL in Oman

1. Language: The first impediment to SCL in Oman is language. The official language in Oman is Arabic. Thus most of the students were taught in Arabic in their primary and secondary education. There was an automatic shift from Arabic to English when they enrolled in colleges as the medium of instruction is English. One teacher pointed out that "because the students' English language is weak, it affects their performance in class. They can hardly speak; when they do it is very little English. Thus they are unable to have effective discussion in class. They have to have a wide range of vocabulary, good comprehension skill, reading skill etc to function well in class". Probing more to find out if students' level of participation in class is low because of low language level, the author asked Arabic speaking teachers if there were differences in the degree of students' participation in the class room when the teacher uses either Arabic or English as a medium of instruction. It was found that in most cases when the teacher uses Arabic, the students performance, and activeness in the class improved dramatically because they understand the concepts better, and are able to express themselves, as opposed to when English is used. One teacher had this to say "when I use Arabic, even those who can't say anything in English, chip in something meaningful in Arabic". The students confirmed the above assertion when the same question was posed to them. As one student said "Arabic is my first language, I speak it at home, in the hostel, with my friends, I studied in Arabic in my secondary school, I understand better when my teacher speaks Arabic. I like English, but my vocabulary is poor, so how can I talk in class?"

2. Culture: Culture plays a big role in negating SCL in Oman. This is because, as is customary, students of the opposite genders can hardly be grouped to work together. Thus it is impossible to see males and females working as a group in or outside the classroom. This affects active learning. The teachers I spoke to in the focus group discussion were in agreement. From records it has been observed that female students do better and understand better than boys during lectures, tutorials, discussions etc. 
Girls participate and contribute better than boys in the classroom. Thus it is expected that were these boys and girls to work together in groups, it is most likely that the boys would pick up, become more active, and participate more in activities in the classroom. However it is interesting to note as one teacher observed that "students in third and final years collaborate more in class than foundation students" The reason according to the teacher is that the former are "more exposed, confident, and independent" as opposed to the later who are" timid; lack self confidence and exposure".

3. Lack of exposure: Closely linked to the issue of culture is students' lack of exposure to interact in class. In most cases when there are presentations, debates, discussions etc in class, some of the boys and the girls as well feel so shy to contribute to such activities. The boys would rather prefer an all boys' class just like the girls. It has been observed that all the boys take very active part in an all boys' class as opposed to a mixed class. The same applies to girls. In fact the author has had many students who preferred getting zero to having presentations in a mixed class. One female student said "we are not used to talking before the boys, we don't interact with them, the classroom does not make any difference". One teacher while speaking on this issue showed a letter written by his students that read in part “...we are from group 30 . We have presentation tomorrow and we want to separate the boys from the girls because this will affect our performance..."

4. Exported teaching materials: The curricula in most cases are not home grown. They are rather exported from western countries. Consequently the course contents may not be so relevant to the culture of the students. When this is the case, students hardly take part in classroom activities that they find aberrant or culturally insensitive. Then again, most of the examples, illustrations, analysis used in the exported curricula are alien to the students. They find it difficult to follow such examples. In the contrary, students are actively involved in teaching and learning when local examples, illustrations and analysis are used. As one teacher in the focus group discussion said " I don't use the case studies from New Zealand because the concepts are difficult, they don't reflect the culture of the students, the students don't follow when these are used, but on the contrary, when I use local examples, the students become more active." Another teacher was of the view that "power point presentations have limited students zeal to read" These students, the teacher went on, "simply depend on power point presentations, they do not read other prescribed course materials or go to the library to borrow books on the subject".

5. Students' poor perception of SCL: Another setback to SCL in Oman is students' poor perception of the concept. Most of the students believe in the traditional method of teaching where teachers are the sole authority in the classroom. The teachers are seen as the reservoir of knowledge and thus should transfer such knowledge to the empty brains of the students. The author has experienced many cases where attempts were made to foster SCL, but many students frowned at it. They felt the "teachers were transferring their teaching duties to them". Their argument is that "teachers are paid to teach, therefore, teach they must!" There have been cases where students protested against calling on them to make contributions in class. In some other cases they asked the teachers how much the teachers will pay them to participate in, explain, or discuss content related issues in the classroom. 
In a discussion with the students as to their roles in the class, most of them said "we have only to sit, listen and take information from the teacher". There have been cases according to one teacher "where passive students complained that active students should stop wasting the time the teacher should use in feeding the whole class information". Any information that is not from the teacher, for the passive students, is not good enough to be accepted. Thus passive students believe that it may be impossible to learn from their fellow students. One student bluntly said "what can I learn from my fellow student? He is just like me, but the teacher is trained and paid to teach us so he has better information".

6. Social Loafers in groups: This is another factor that militates against SCL. In as much as group or team work is desired and yields good result as far as SCL is concerned, its bane remains that some students do not take part in the group work especially outside the classroom. They leave it for their friends to do. In this case learning does not take place as the loafers do not take active part in problem solving, yet they may pass the exam. One of the teachers added that she has found out that "when students are paired, the weak students would usually want to be paired with bright ones. This is good, but in most cases the weak students leave the work for the bright students". A student confirmed this when he said that "I don't like to work in a group because I usually ended up doing the assignment alone'.

7. Lack of proper teaching methodology: It has often been said that at the very center of SCL is the teacher. It is obvious to say that the teacher in most cases makes or mars SCL. Bad teaching methodology does not encourage SCL. What is bad teaching methodology? It includes excess Teacher Talking Time (TTT), lecturing, power concentration on the teacher rather than sharing control with the learners. As Scrivener (2005) says of a good teacher "... But the teacher I recall with most pleasure and respect was the one who listened to me, who encouraged me, who respected my own views and decisions. Curiously, this teacher.... was the one who actually did least 'teaching' of the subject matter and was seemingly, technique-free, being basically 'himself' in class. My memories of his lessons are of what I did, rather than what he did, of my learning rather than his teaching". The teachers were in agreement to the above assertion. Some of them argued that difficult course contents and time constraint leave them no option than to spend more time in explaining the concepts.

8. Lack of well equipped libraries: Poor libraries and lack of access to electronic books and journals are also barriers to SCL in Oman. It was observed that the Learning Resource Centers are not well equipped in terms of books and there is hardly any access to electronic materials. Thus students do not engage in reading as some of the prescribed materials may not be available in the LRC. In as much as this is a major problem, one of the teachers was quick to point out that "a more serious problem is the lack of reading culture among students in this country. Even if the libraries are well equipped, the students hardly have time to engage in reading. Omani culture is rich in oral tradition, not reading".

9. Readymade materials: Most of the materials used in teaching in Oman are readymade especially if they were sourced from western countries. The students rely heavily on these materials to the point that, as most of the teachers agreed, "They 
don't take notes in classes". One teacher added that during "my school days my teachers used to introduce the topics and we would go to the library to read more about them, this helped us to develop critical thinking skill, and do research oriented work but this is not the case in Oman, students only rely on teachers and power point materials".

\section{CONCLUSION / RECOMMENDATIONS TO IMPROVE SCL IN OMAN}

Student-centered learning, as desirable as it is, faces numerous problems in its implementation all over the world. Oman is no exception. Thanh, (2010), Sablonnière et al (2009) in their different studies on the impediments to implementing SCL in Vietnam, and Kyrgyzstan respectively found out that the major problem is moving beyond the status quo. In Oman the problems in implementing SCL are more than moving beyond the status quo as this study has revealed. Here in lies the significance of this study - identifying the barriers to SCL in Oman. In reviewing related literature to this study, the author did not find any work on barriers to SCL in Oman; this study is therefore novel and will add to body of knowledge on the topic in and outside Oman.

Given that Oman has invested much in the education of its teeming youth population in schools, colleges, and universities, it embarked, as Al-Nofli (2010) noted, on reforms that focused heavily on the implementation of student-centered strategies, including cooperative learning, inquiry, and role-playing. In line with this trend, Al-Nofli went on; greater emphasis has been placed on implementing formative assessment methods such as class observations, student projects, short quizzes, self-assessment, and other useful methods. But contrary to expectations as revealed by the present study, SCL is yet to take a deep root in Oman. Based on this the author has come up with the following recommendations to help SCL succeed in Oman.

- English Language level of the students needs to improve dramatically to empower the students to read, and comprehend their study materials. The student's mastery of the language has to be at the level that will enable them to participate actively in class. Students should be introduced to English Language early enough, right from primary level.

- Students should be encouraged to have meaningful participation between the genders in class within the limits of what is acceptable. They could work in groups supervised by the teacher; the social distance in such groups should be culturally comfortable for the students. The idea is to get all the students actively involved in classroom activities. This will also encourage weak students to draw strength from brighter students.

- Teaching and study materials should be written to suit the students. They should include more local rather than foreign contents. Examples, illustrations, case studies etc in the course materials and in fact the whole course materials must be culturally sensitive, and written in way that students can easily read and understand the contents.

- Students need to have a better understanding of what SCL is. There is need for them to know what roles they are expected to play in class. They should be reoriented to understand that traditional method of teaching has no place in the present dispensation. Thus there is need for attitudinal change on the part of students about 
SCL. Students should play an active role in the process of teaching and learning rather than playing a passive and receptive role.

- Teachers in playing supervisory roles in students' group work have to ensure that all hands are on deck in problem solving. While emphasizing interaction through group work, the individual student's initiative should also be encouraged.

- Students should be involved in curriculum design; students' assessments should be done with the view to encourage improvement rather than competition among the students.

- It is pertinent that teaching methodology should only be employed to empower students and not the teacher. Any teaching methodology that does not put the students on the center stage is anti SCL. Teachers should therefore ensure, no matter the circumstances, that teaching pedagogy strongly encourages students' participation in the class.

- Parents/families also have a role to play in encouraging their wards to socialize and take active part in classroom activities. Academic socialization should not be seen as a taboo. It should rather be encouraged as it is geared toward academic excellence.

- Lifelong learning should be encouraged among students. Presently most of the students study for utility - just to pass exams. Thus it is not strange for students to memorize relevant course materials and regurgitate them during exam. There is need for proper understanding and synthesizing of the course content by the students. Teachers therefore need to go beyond power point teaching style and introduce students to additional course resources. This will broaden their understanding of the subject matter.

- Learning resources should be adequate to support teaching and learning. This will help the students to develop their critical thinking skills and engage in research oriented study.

CONCLUSION: It has often been said that the brain eliminates connections that are seldom used. When it comes to learning, it's either that students use their brain or lose it. The only way they can use their brain effectively is to be fully engaged in active or student-centered learning. Neurologists and cognitive scientists believe that people literally build their own minds throughout life by actively using their brain to organize and connect bits of isolated information. This is what active learning is all about. SCL should provoke diverse reasoning, problem solving, and critical thinking or independent thought thereby creating a lifelong learning in students. Teachers, students, and education providers should all work together to ensure the successful implementation of SCL in Oman 


\section{REFERENCES}

Bean, J. "Engaging Ideas, The Professor's Guide to Integrating Writing, Critical Thinking, and Active Learning in the Classroom." San Francisco: Jossey Bass, 1996.

Black, P. (1999). Assessment, learning theories and testing systems. In Murphy, P. (Ed) Learners, Learning and Assessment. London: Open University Press.

Brenda Hall. (2006). Student centered Learning from http://secondlanguagewriting.com, accessed on 3/20/2012.

Brown, S, Rust, C, and Gibbs, G (1994) Involving Students in Assessment. In Strategies for Diversifying Assessment in Higher Education. Oxford: The Oxford Centre for Staff Development.

Brush, T and Saye, J (2000) Implementation and Evaluation of a Student-Centered Learning Unit: A Case Study. In Educational Technology Research and Development, vol 48, no 3.

David A. Garvin (1991) Barriers and gateways to learning, http://hbsp.harvard.edu/multimedia/pcl/pcl_1/resource1/document.pdf._Accessed on 2/4/2012

Gokhale, A. A. (1995) Collaborative Learning Enhances Critical Thinking, Journal of Technology Education, Vol 7, no 1.

Jim Scrivener (2005) Learning Teaching. United Kingdom, Macmillan Publishers limited.

Kember, D. (1997). A reconceptualization of the research into university academics conceptions of teaching. Learning and Instruction, Vol 7, no 3

Lea, S.J., Stephenson, D., and Troy, J. (2003) Higher Education Students' Attitudes to Student Centered Learning: Beyond 'educational bulimia'. Studies in Higher Education Vol 28 , no 3.

Liamputtong, P. (2011) Focus Group Methodology: Principle and Practice CA: Sage Mohammed Abdullah Al-Nofli (2010) Perceptions of social studies teachers about social studies goals and content areas in Oman. In European Journal of Educational Studies vol.2, no. 2.

Panitz, T. Benefits of Cooperative Learning in Relation to Student Motivation, in Theall, M (ed) (1999) Motivation from within: Approaches for encouraging faculty and students to excel, New Directions for teaching and Learning, issue 78.

Pendersen, S. and Liu, M. S. (2000) Student Centered Learning Environment, http://www.columbia.edu/ 1sb31/Student_centered.pdf accessed on 14/ 03/ 2012.

Sablonniere de la Roxane, Taylor D. M, and Sadykova, N, (2009) Challenges of applying a student-centered approach to learning in the context of education in Kyrgyztan in http://www.sciencedirect.com/science/article/pii/S0738059309000029 accessed on $14 / 03 / 2012$

Than-Pham, T. H (2010) Implementing a Student-Centerd Learning Approach at Vietnamese Higher Education Institutions: Barriers under Layers of Casual Layered Analysis (CLA) in Journal of Futures Studies vol 15, no 1

Sablonniere de la Roxane, Taylor D. M, and Sadykova, N, (2009) Challenges of applying a student-centered approach to learning in the context of education in Kyrgyztan in http://www.sciencedirect.com/science/article/pii/S0738059309000029 accessed on $\underline{14 / 03 / 2012}$ http://www.infed.org/thinkers/et-freir.htm. (on Paulo Freire, accessed on o4/03/2012) 
http://www.gdrc.org/kmgmt/c-learn/index.html, ( on collaborative learning accessed on 04/03/2012) 